\title{
A FAZENDA CABACEIRAS E A NARRATIVA CAMPONESA EM UMA AÇÃO POSSESSÓRIA
}

Emmanuel Oguri Freitas ${ }^{1}$

Ana Maria Motta Ribeiro ${ }^{2}$

\begin{abstract}
RESUMO
Este trabalho é fruto de uma pesquisa que abordou a utilização da categoria trabalho escravo como elemento principal utilizado na luta pela permanência na Fazenda Cabaceiras, no Sudeste do Pará. Trata-se da primeira fazenda desapropriada por degradação ambiental e trabalho escravo no Brasil. Em Cabaceiras, analisamos alguns processos que se apresentam como campo de disputa entre trabalhadores e proprietários. O princípio da função social da propriedade passava a ser apresentado como base moral/legal de ambas as partes. Através da investigação feita nos debates e nas descrições apresentadas nos autos, pretendemos refletir acerca da disputa entre posições, evidenciando as estratégias de ambos os sujeitos e revelando o movimento de apropriação da narrativa camponesa pelo discurso oficial do Estado.
\end{abstract}

Palavras-chave: Fazenda Cabaceiras, Trabalho Escravo, Narrativa Camponesa.

\section{THE CABACEIRAS FARM AND THE PEASANT NARRATIVE IN A POSSESSORY ACTION}

\begin{abstract}
This work is the result of a research that approached the use of the slave labor category as the main element used in the fight for the permanence in the Cabaceiras Farm, in the southeast of Pará. It is the first farm expropriated by environmental degradation and slave labor in Brazil. In Cabaceiras, we analyze some processes that present themselves as a field of dispute between workers and owners. The principle of the social function of property was now presented as the moral / legal basis of both parties. Through the investigation made in the debates and descriptions presented in the file, we intend to reflect on the dispute between positions, highlighting the strategies of both subjects and revealing the movement of appropriation of the peasant narrative by the official discourse of the State.
\end{abstract}

Keywords: Cabaceiras Farm, Slavery, Peasant Narrative.

\section{INTRODUÇÃO}

A investigação que apresentamos neste artigo percorreu a história de luta pela terra que envolve o imóvel 'Fazenda Cabaceiras' no sudeste do Pará. As disputas entre os diversos atores que participam desse universo - composto por Comissão Pastoral da Terra (CPT), Movimento dos Trabalhadores Rurais Sem-Terra (MST), Instituto Nacional de Colonização e Reforma Agrária (INCRA), Organização Internacional do Trabalho (OIT), Ministério Público do Trabalho (MPT), trabalhadores escravizados e proprietários - se apresentam nesse cenário em que a propriedade e o trabalho são mediados pelo instituto constitucional da função social da propriedade. Neste artigo,

\footnotetext{
${ }^{1}$ Doutor em Sociologia e Direito pelo PPGSD-UFF. Professor do Curso de Direito da Universidade Estadual de Feira de Santana- UEFS/BA. Membro do Observatório Fundiário Fluminense. emmanuel.of@gmail.com

${ }^{2}$ Doutora em Ciências Sociais em Desenvolvimento, Agricultura e Sociedade. Professora de Sociologia da Universidade Federal Fluminense. Líder do Observatório Fundiário Fluminense. anamribeiro@,outlook.com
} 
tratamos, especialmente, da ação possessória $n^{0}$ 028.1998.1.001033-1, interposta pelos fazendeiros para impedir a entrada dos sem-terra na área ${ }^{3}$.

As construções representativas apresentadas pelos debates judiciais apontam para uma luta pela hegemonia da definição e significação da propriedade e da terra. Nesse processo, a imagem narrada surge com intenção de 'falar por si só', pressupondo um campo semântico próprio e compartilhado que responderá automaticamente à descrição apresentada, pretendendo uma certa universalidade.

A possibilidade de protagonismo de uma narrativa camponesa parece se tornar viável, no caso desse processo judicial, no momento em que o conceito de trabalho escravo contemporâneo passa a oferecer ao movimento de luta pela terra um sentido de vida possível: combater a injustiça do latifúndio. Afinal de contas, acreditamos, assim como Thompson (1997, p.354), que "o direito pode ser retórico, mas não necessariamente uma retórica vazia”, visto que seu uso através de ações judiciais e denúncias em tribunais internacionais tem sido estratégias mobilizadas pelos movimentos sociais.

Para dar conta de analisar as estratégias e manobras ${ }^{4}$ reveladas pelos sujeitos da luta no processo judicial, estruturamos este artigo em três seções. Na primeira, oferecemos uma imagem do conflito que se dá em torno da propriedade da terra na Fazenda Cabaceiras e defendemos o uso metodológico do processo judicial como possibilidade de investigação da luta de classes. Na segunda parte, apresentamos de forma mais detida os três sujeitos principais da história que pretendemos rememorar: a CPT, o MST e a família Mutran - a antagonista no processo judicial que pretendemos apresentar aqui neste artigo.

$\mathrm{Na}$ terceira seção, apresentamos a disputa nos autos do processo judicial, analisando as provas apresentadas, discursos defendidos por cada parte e a configuração do que denominamos narrativa camponesa. Por fim, relatamos a contribuição que o presente estudo pode oferecer à pesquisa sobre as diversas formas de agências dos subalternizados.

\section{CABACEIRAS E A NARRATIVA DA LUTA A PARTIR DO PROCESSO JUDICIAL}

Mulheres e homens que ocuparam as terras da antiga Fazenda Cabaceiras, no sudeste do Pará, no ano de 1998, têm contado para nós uma história de luta e resistência que pode ser considerada vitoriosa, já que foram capazes de impulsionar a primeira desapropriação-sanção por reincidência na

\footnotetext{
${ }^{3}$ As ações possessórias visam dar segurança ao exercício da posse do imóvel. Estão previstas entre os artigos 554 e 568 do novo Código de Processo Civil.

${ }^{4}$ Utilizamos as ideias de estratégias e manobras como chaves explicativas para compreensão das performances apresentadas pelos movimentos sociais de luta pela terra e pelos proprietários nas disputas por terras no sudeste do Pará. Cf. FREITAS, Emmanuel Oguri. A Devolutiva como Prática Dialógica/Dialética da Sociologia Viva do Observatório Fundiário Fluminense: O caso da luta pela terra na Fazenda Cabaceiras. Confluências, Niterói, v. 21, n. 2, p. 179-195, ago. 2019.
} 
prática de escravizar trabalhadores. Aqui assumimos a descrição do processo de lutas como uma narrativa, ou contranarrativa, em que os subalternizados alcançam, através da ação coletiva, entre perdas e conquistas, uma modificação efetiva de sua situação anterior.

Nessa perspectiva, acreditamos poder distinguir de forma mais apurada a luta de classes, em detrimento da ação de cada classe em separado. Desse embate, veremos em que medida saem modificados tanto os sem-terra, quanto os fazendeiros. Insistimos na tarefa de construção de uma forma de apreensão do real "em movimento", agenciado por sujeitos vivos que produzem uma história que se condensa em documentos, permitindo acesso para compreensão do pesquisador.

No processo judicial, onde nos é facilitada a observação da luta de classes, nos são oferecidos elementos importantes (estratégias, manobras, resistências e imagens/narrativas) para compreensão das formas de sociabilidade reproduzidas pela sociedade capitalista (Varella, 2002; Ginzburg, 1993; Thompson, 1998). Optamos pela análise tendo como ponto de partida o método do materialismo histórico dialético e, através dele, abordamos o campo jurídico e o processo de construção de imagens do movimento social de luta pela terra, que, ao cabo, influenciou a produção de uma 'narrativa oficial' sobre função social da propriedade. Nos processos judiciais referentes ao imóvel estudado, procuramos perceber as versões dos grupos envolvidos no conflito fundiário. Vasculhando a história a contrapelo, pretendemos analisar a narrativa camponesa. Que história é contada por aqueles a quem o progresso insiste em querer apagar?

O processo histórico consolidado, que em geral aparece beneficiando as classes dominantes, de acordo com Benjamin (2012), é produto de luta na qual os oprimidos também produziram o resultado e, aqui, será considerado como narrativa oficial, ou história oficial. Há um consenso de que a história da propriedade da terra no Brasil sempre esteve ligada ao domínio de vastos territórios por setores das classes dominantes, restando à boa parte do campesinato as sobras, terras desprezadas e os "contratos" tradicionais de uso da terra, pautados pela lógica do favor e do compadrio (Motta, 1998; Sigaud, 1996; Moura, 1978).

A contranarrativa, da forma que estamos propondo, se refere ao processo de luta pela terra organizada pelos subalternizados em atos, práticas e reflexões, e não como modelo sistêmico fechado em si. Ela é uma agência política dos subalternizados na tentativa de se estabelecer e ganhar a luta contra, ou sobre, a narrativa oficial. A partir da narrativa oficial, buscaremos extrair a produção própria dos camponeses, que se pretende emancipatória, visto que o caso Cabaceiras é um dos poucos exemplos em que essa contranarrativa consegue imprimir um conteúdo material à narrativa oficial.

Da ação possessória referente ao imóvel, em que o juiz determinou três reintegrações de posse em favor dos antigos proprietários da Fazenda Cabaceiras, podemos colher essa contranarrativa. Nesses tipos de ação, quando interpostas em varas cíveis comuns, basta a interpelação judicial acompanhada do título de propriedade que os juízes, majoritariamente, tendem a conceder a liminar 
de reintegração de posse. Em estudo de Quintans (2011) sobre as varas agrárias do Pará, ficou comprovado que a especialização dos magistrados em direito agrário aponta para a possibilidade de se romper com este padrão que encaminha com grande frequência liminares de reintegração de posse para o fazendeiro nesses casos de disputa.

Os autos processuais apresentam variadas imagens que se multiplicam. De um lado, semterras retratavam as figuras de proprietários mesquinhos que teriam se apropriado de terras públicas com o uso da violência. De outro lado, os proprietários falavam em uma situação de desordem geral e caos criado pela ação dos 'invasores' em fazendas de todo o estado e pelo país. A posição do poder público se apresenta dividida a depender da esfera de exercício e do habitus compartilhado (Bourdieu, 2010). Delegados e juízes parecem se sentir mais tocados pelo discurso patronal. Os promotores de justiça se desviam de envolvimento nas ações possessórias, mas atuam de maneira irresoluta nas ações penais.

No embate entre duas visões sobre a terra, os proprietários se pretendem semeadores de progresso, enquanto o MST se propõe a modificar a maneira como o desenvolvimento das forças produtivas se articula com as questões relativas ao território, trabalho e natureza. Esse é um dos debates centrais que pretendemos desenvolver, uma vez que o caso analisado possibilita a percepção do antagonismo entre a visão de uso da terra para a produção familiar de gêneros alimentícios para subsistência e venda no mercado local, com o respeito às questões trabalhistas e ambientais, em oposição a uma visão de apropriação da terra com base no título de propriedade para destinação a formas de produção pretensamente modernas, com incremento tecnológico, monocultora e voltada para o mercado internacional.

\section{O CENÁRIO DA PESQUISA E OS SUJEITOS DA DISPUTA}

O caminho que liga Marabá até Eldorado dos Carajás é cheio de fazendas emblemáticas na localidade, algumas por conta das histórias de luta, outras pelas dimensões territoriais inimagináveis, e quase todas pela violência que reproduziram. Entre elas, encontra-se a antiga Fazenda Cabaceiras, conhecida em toda a região por conta da centralidade dada pelos noticiários, em razão das reportagens sobre a ocupação da terra em 1999 e das diversas denúncias de trabalho escravo, acompanhadas da descoberta de um cemitério clandestino na área.

A região sudeste do Pará teve suas primeiras denúncias acerca da violência estrutural em que vive na década de 1970. A carta de Dom Pedro Casaldáliga, que data de 10 de outubro de 1971, apontando os custos humanos impostos por latifundiários e projetos de colonização iniciados nos tempos sombrios dos governos militares, foi a primeira iniciativa para dar visibilidade ao grave problema na região (Casaldáliga, 1971). A criação da CPT foi determinante para o início do combate 
ao trabalho escravo na região, tendo em figuras como Xavier Plassat, Frei Henri DesRosiers e Ricardo Rezende Figueira enquanto alguns dos mais combativos religiosos dispostos a enfrentar a situação.

Desde essa época até os dias atuais, a articulação e a assessoria têm sido as formas de intervenções políticas mais significativas realizadas pela CPT. Entretanto, a denúncia da situação de miserabilidade e escravidão dos trabalhadores rurais atribuiu ao papel de mediadores de seus agentes um elemento a mais: passariam a produzir e divulgar dados sobre violência e escravidão no campo. Relatórios e cadernos de conflitos no campo passaram a ser publicados a partir de 1985, tendo fornecido uma base de dados utilizada até os dias atuais em pesquisas acadêmicas e pela militância. No que tange à questão do trabalho escravo, essa iniciativa começou a produzir efeitos a partir da década de 1990.

Antes da chegada do MST ao Estado do Pará, a luta por terras empreendida por posseiros era expressa por três elementos nas fronteiras amazônicas: o homem, a arma e o lote (Guerra, 2013). Os fluxos de chegada de camponeses, trabalhadores, fazendeiros, empreiteiros e infraestrutura se intensificaram na década 1970 (Ianni, 1979). Com isso, ficou muito evidente a perversa apropriação do trabalho realizada pelas empreitadas, chamando atenção dos membros das pastorais.

Em 1989, com a chegada do MST no Estado do Pará, a CPT local ganharia um aliado na tarefa de denunciar condições de exploração do trabalho escravo contemporâneo. Apesar da dificuldade de territorialização do MST na região Norte, a fixação do movimento naquela área trouxe novidades em relação à ocupação do espaço público no que tange à questão agrária. Os trabalhadores sem-terra passaram a ocupar as fazendas nas beiras das estradas, ao invés da tradicional ocupação escondida dos olhos dos fazendeiros, sustentadas pela posse direta da terra e pela defesa armada.

O cenário composto por diversos sujeitos que denunciavam a existência do trabalho escravo e a injustiça dos latifúndios improdutivos resultou na possibilidade de ocupação da Fazenda Cabaceiras. Com o apoio técnico, através da assessoria de advogados e técnicos agrícolas, militantes do MST ocuparam o imóvel em 26 de março de 1999. Deram início a uma batalha judicial de nove anos, até a imissão na posse, onde as estratégias estabelecidas e a fé na resistência propiciaram a conquista da terra.

O primeiro contato que tivemos com o processo judicial da ação possessória de Cabaceiras foi muito proveitoso para compreender o cenário, pois possibilitou conhecer alguns dos sujeitos que escreveram a história da ocupação. A referência aos processos judiciais como forma de reconstrução da história, como procedemos no estudo sobre Cabaceiras, é uma constante no nosso modo de investigação. Diversos autores têm explorado essa metodologia, onde, como se sabe, deve-se proceder à mediação entre o que é registrado no processo judicial e o que se coloca como fala dos sujeitos participantes (Varella, 2002; Ginzburg, 1993). A dificuldade em se obter dados sobre a 
atuação dos oprimidos tem sido sanada com a observação de suas falas em processos judiciais, literatura popular e notícias da imprensa (Ginzburg, 2006; Motta, 1998; Thompson, 1987).

O caso de Cabaceiras foi noticiado como a primeira fazenda desapropriada por existência reiterada de trabalho escravo e degradação ambiental. Seu nome figurou em alguns noticiários em dois momentos, em outubro de 2004, quando foi assinado o decreto de expropriação, e em dezembro de 2008, quando finalmente ocorreu a imissão na posse do INCRA, regularizando a situação dos que permaneceram na ocupação. A repercussão foi nacional.

Tendo como base elementos de resgate dessa história, filiamo-nos aos problemas trazidos por Benjamin (2012), que, em seu ensaio intitulado Sobre o conceito de História, nos propõe que a tarefa da historiografia crítica seria o estudo na perspectiva dos oprimidos. Uma sociedade somente poderá se considerar liberada, quando resgatar a história dos subalternizados, daqueles que, no processo da luta de classes, tornaram-se sujeitos da prática que constrói a história, bem como sujeitos do conhecimento histórico.

Esse movimento que, com base nos historiadores marxistas britânicos, denominamos from the bottom up (Thompson, 1978; Kaye, 1984) é acompanhado pela ação de frações da classe proprietária e deve ser pensado em relação, num contexto de luta de classes. Com efeito, apresentamos o outro sujeito a quem os membros do MST pretendiam antagonizar, representado pela família Mutran que tem sido reconhecida na região pela violência com que trata a terra/natureza e os trabalhadores.

Ainda povoa o imaginário e as místicas dos movimentos sociais a história do menino Zé Pereira, que, em 1989, aos 17 anos, foi alvejado e morto por tentar fugir da fazenda Espírito Santo, de propriedade de Benedito Mutran, onde se encontrava escravizado. O caso chegou à Corte Interamericana de Direitos Humanos em 2003, dando visibilidade ao estado de violência e barbárie que impera na região ${ }^{5}$.

Os Mutran são membros da sociedade paraense que alcançaram a riqueza material e política, uma vez que, além de serem proprietários de terras e imóveis em toda extensão do estado, assumiram, por vezes, cargos políticos no legislativo e no executivo. Nagib e Vavá (PMDB) foram deputados estaduais, sendo que o primeiro ainda foi vereador e o segundo elegeu-se prefeito de Marabá. Guido Mutran (PFL) foi empossado como vereador de Marabá como suplente de Nagib. Anderson Mutran Júnior (PMDB) e Osvaldo Mutran Júnior (PMDB-PFL) também exerceram vereanças no município de Marabá.

A família Mutran foi um dos antagonistas escolhidos pelo MST, pois simbolizaria o patrimonialismo e a violência típicos do cenário rural amazônico. $\mathrm{O}$ enfrentamento desse clã revelaria

$5 \mathrm{O}$ caso do processo da morte do menino Zé Pereira foi resolvido com a petição número 11.289, onde o Estado brasileiro se comprometeu a continuar tentando cumprir os mandados de prisão contra os acusados pelo crime. Cf. http://www.cartamaior.com.br/?/Editoria/Direitos-Humanos/Os-negocios-da-familia-Mutran/ 5/1169 Acessado em $12 / 05 / 2016$. 
a necessidade de luta constante e a urgência de uma nova forma de combate que pudesse dar conta de desconstruir poderes e relações espúrias construídas ao longo do tempo no processo de colonização da região.

\section{A FORMA ACAMPAMENTO EM NOVOS ENFRENTAMENTOS NA CONFIGURAÇÃO DE UMA NARRATIVA CAMPONESA}

Encarando de frente o elemento da luta de classes, o MST apresenta à sociedade paraense a forma acampamento (Sigaud, 2000) que passa a construir diversas imagens. As representações patrocinadas por parte da mídia e pelo discurso dos fazendeiros aparecem no processo judicial sob a forma de "barbárie", "desrespeito ao Direito Pátrio", "atitude agressiva, violenta e desrespeitosa", assim como tantas outras que surgem nas diversas peças processuais e administrativas analisadas. $\mathrm{O}$ papel da imprensa paraense é bastante dúbio, pois algumas vezes reforça o papel transgressor do movimento e em alguns poucos momentos apresenta a família Mutran como reconhecidamente violenta.

Acreditamos, assim como Benjamin (2012, p. 242), que "somente para a humanidade redimida o seu passado tornou-se citável, em cada um de seus momentos". O estudo da ocupação da fazenda Cabaceiras pode oferecer uma lição para o presente, ora que se encontra impregnado de passado, permitindo que o futuro se concretize enquanto cenário de oportunidade de mudança.

Para dialogar com os elementos que conferem legitimidade no campo jurídico, categorias como função social da propriedade, trabalho escravo, propriedade privada e a questão ambiental passaram a oferecer a pauta das disputas. Apesar de se tratar de estudo de caso, temos constatado que as mesmas categorias aparecem em debates locais e nacionais, permitindo, a partir do caso específico, pensar a questão agrária e a atuação de movimentos sociais num aspecto mais amplo.

Podemos destacar o interdito proibitório que foi interposto pelo fazendeiro ${ }^{6}$ que nos oferece um cenário importante para perceber a tensão entre os discursos e a sensibilidade do Judiciário para sopesar as pretensões. O interdito proibitório é um tipo de ação que visa impedir o que os agentes do campo jurídico classificam como turbação ou esbulho ${ }^{7}$ da posse, visando garantir o exercício da posse, conforme se pode perceber na leitura do artigo 560 do Código de Processo Civil ${ }^{8}$. No processo, o juiz prontamente atendeu o pedido do autor em um tipo de decisão que tem certa regularidade nos tribunais brasileiros.

\footnotetext{
${ }^{6} \mathrm{Na}$ ação, figura a empresa que era proprietária das terras da Fazenda Cabaceiras, denominada Jorge Mutran Exportação e Importação LTDA.

${ }^{7}$ No caso de propriedade rural, a turbação é a perda da posse de uma parte da terra, enquanto o esbulho se refere à totalidade da gleba.

${ }^{8}$ Código de Processo Civil, Art. 560. O possuidor tem direito a ser mantido na posse em caso de turbação e reintegrado em caso de esbulho.
} 
A decisão do juiz tem por base dois fundamentos, um de natureza jurídica e outro de natureza social. No campo jurídico, basta provar a posse e o "justo receio" ou possibilidade de turbação. O "justo receio" consistiria na necessidade de demonstrar ao magistrado que alguns elementos da realidade indicariam a iminência da prática de qualquer ato que venha a impedir o livre exercício da posse de um imóvel. Em relação a esse quadro, o juiz parece ter ficado bem à vontade para explicitar a percepção dos requisitos.

No que tange ao elemento social, o juiz apresenta a subjetividade de sua percepção do mundo para definir o justo receio alegado pelo autor e dispensar a oitiva dos 'requeridos', no caso, os ocupantes. Assim, o juiz justifica textualmente sua decisão de deferimento da liminar e expedição de mandado proibitório: "nesta região em especial e no País inteiro, lamentavelmente, vive-se nessa onda de invasões e desrespeito à propriedade quer do particular, quer do Governo" (Pará, 1998, p. 32).

Ainda na primeira decisão do processo, podemos identificar no discurso elementos de desqualificação dos trabalhadores rurais através do uso de uma retórica bastante ideologizada e discriminatória, que lança mão de determinadas qualificações pejorativas: 'desestabilização fundiária'; 'declaração audaciosa, irresponsável e inconsequente'; 'atitude agressiva, violenta e desrespeitosa'; bem como alusão à necessidade de se impedir que se repita o caso Eldorado dos Carajás. Esta decisão data de 27 de março de 1998. Ocorre que o movimento social ocupou, de fato, a Fazenda Cabaceiras em 26 de março de 1999, reabrindo o debate judicial.

Procuramos, por outro lado, compreender que componentes são resgatados pelos ocupantes para construir sua própria narrativa. A forma como os argumentos são tratados pretende evidenciar o núcleo dos discursos, que, apresentado como fala própria do movimento, termina por se configurar contranarrativa, rompendo com a forma anterior, centrada nas falas dos proprietários.

Com um ano e dois meses de ocupação da fazenda Cabaceiras, estamos produzindo o que essa fazenda nunca produziu. Estamos cumprindo com uma função social que antes não cumpria. Avançamos não somente na produção de alimentos como também na educação de novo povo (Sic). (Pará, 1998, p. 590).

Podemos observar, portanto, no trecho de entrevista apresentada nos autos processuais que, no contexto das disputas por significados, o MST se apropria de elementos como função social, produtividade, acesso à educação e agricultura de subsistência para legitimar ou conceder "dignidade pública e grandeza social” para sua participação (Rosa, 2012, p. 102).

Através de notícias de jornal, o advogado dos requeridos (os ocupantes do imóvel) tenta demonstrar três elementos que poderiam reverter a decisão do juiz: os ocupantes do imóvel não são os mesmos da disputa que ocorrera um ano antes, impossibilitando que a ação de interdito proibitório fosse convertida em reintegração de posse; a propriedade é injusta, pois tratam-se de terras públicas 
que teriam sido objeto de grilagem; e, por fim, porque a reintegração pode ser muito penosa para as famílias na área, com possibilidade de resultar em atos de violência contra os ocupantes.

Este último traço tem relação, ainda, com a ideia de estado de necessidade, uma vez que o único caminho possível para as famílias de sem-terra é do acesso à propriedade pela ocupação. Diante dos elementos trazidos na petição, solicita que seja revogado o mandado liminar de reintegração de posse, bem como a intimação do Ministério Público para participar da ação judicial.

O advogado dos ocupantes apresenta, ainda, uma reportagem de jornal que conta a situação dos acampados na fazenda Cabaceiras. Os sem-terra estavam com pouca comida e, devido ao tamanho da ocupação, só restavam mantimentos para mais 4 dias em 30 de março de 1999. Sobreviviam quebrando coco do babaçu e da caça de pequenos animais silvestres que podiam ser encontrados nas matas da fazenda. O clima de tensão era muito grande, de maneira que a segurança dos acampados vinha sendo reforçada no rodízio característico das ocupações dos sem-terra. Era grande o receio de que o gerente da fazenda estivesse organizando uma milícia para proceder a uma desocupação.

Os depoimentos dos acampados dão conta da extrema necessidade em que viviam e falam da esperança de que aquela atitude radical pudesse garantir uma 'terra para plantar' e 'fazer criação'. Buscavam no MST “uma solução para saciar a fome e uma forma de melhorar de vida" (Pará, 1998, p. 592). De acordo com a referida reportagem, muitos seriam desempregados cadastrados nos municípios de Conceição do Araguaia, Jacundá, Itupiranga, São Domingos do Araguaia e Marabá.

No dia 16 de dezembro de 1999, o advogado do MST solicita a 'juntada' de um novo documento constituído pela revista Caros Amigos (Pará, 1998, p. 602), que traz uma reportagem sobre um cemitério clandestino, possivelmente de trabalhadores escravizados, encontrado no interior da fazenda Cabaceiras. A partir desse momento, entra na disputa simbólica mais um elemento determinante no caso: a imagem do trabalho escravo utilizado na ocupação territorial do sudeste do Pará.

A reportagem intitulada Longe dos olhos dos grandes centros... ressalta o clima de tensão da região sudeste do Pará e utiliza a metáfora do 'barril de pólvora'. Sobre o cemitério clandestino, a reportagem resgata a descoberta dos corpos que ocorrera em junho daquele ano, através de uma denúncia feita pela Federação dos Trabalhadores da Agricultura (FETAGRI) e pela CPT. No cemitério clandestino, teriam sido encontradas 13 ossadas de trabalhadores castanheiros, trabalhadores de derrubada e familiares. Os assassinatos teriam ocorrido do período de 1983 a 1995 , por pistoleiros contratados para fazer a vigilância da fazenda. A denúncia havia sido feita por um trabalhador que conseguiu escapar do imóvel.

De acordo com a testemunha entrevistada por Caros Amigos, alguns corpos haviam sido queimados e, portanto, não foram enterrados. Outros seriam levados de barco pelo rio Sororó para 
serem enterrados como indigentes no cemitério de 'São Miguel', em Marabá. As árvores próximas ao cemitério clandestino teriam sido utilizadas para pendurar os trabalhadores, onde eram torturados e mortos. O denunciante revela que até mesmo uma criança havia sido assassinada na fazenda.

$\mathrm{Na}$ narrativa da reportagem, nem mesmo o trabalho escravo foi capaz de modificar a atuação da Secretaria de Segurança Pública do Pará em relação à situação da Fazenda Cabaceiras. De acordo com Paulo Sette Câmara, responsável pela pasta no governo de Almir Gabriel, o mesmo que era governador na época do massacre de Eldorado dos Carajás, tratava-se de uma armação do MST, que contava com a anuência de 'entidades que denunciam qualquer coisa de forma irresponsável'. Para ele, segundo a reportagem que reproduz entrevista concedida ao jornal O Liberal, em 18 de julho de 1999, o MST teria alterado um cemitério "de mais de décadas", escondendo as cruzes que identificavam as sepulturas.

No dia 9 de julho de 1999, uma equipe da polícia federal iniciou as escavações no local, tendo encontrado duas ossadas com peças de roupas e cordas que teriam sido usadas para amarrar os indivíduos. O trabalho teria sido interrompido para que se trouxesse um perito criminal e um médico legista da cidade de Marabá, com intuito de auxiliar nas identificações. Às 17:30 horas daquele mesmo dia, os trabalhos foram reiniciados, tendo encontrado mais um corpo na cova onde haviam encontrado os outros dois cadáveres. Os policiais encontraram, ainda, o corpo de uma criança, corroborando o relato do denunciante. No dia seguinte, foram localizadas mais três ossadas pela manhã. De acordo com o Instituto Médico Legal de Belém, não havia aparato técnico para analisar as ossadas na região. Até a edição da revista, não havia ocorrido nenhum avanço nas investigações.

O regime de escravidão por dívida seria utilizado na Fazenda Cabaceiras de maneira continuada. Quando os trabalhadores conseguiam um saldo de remuneração e pediam para ir embora, eram pagos e, depois, assassinados por pistoleiros que traziam o dinheiro de volta. Nas reportagens, fala-se das mortes e do cemitério de trabalhadores, alegando não se saber o nome de todos, pois seria difícil conhecer tantos trabalhadores de uma fazenda tão grande.

Um trabalhador entrevistado conta que chegou a presenciar uma caminhonete, conhecida como 'onça preta', cheia de corpos cobertos com folhas de bananeira. Ao olhar debaixo das folhas e notar os corpos, foi repreendido pelos pistoleiros. Enumera, ainda, os nomes dos pistoleiros que prestavam serviço na fazenda: Sebastião da Teresona e João Passos, já mortos, Felão, Deodato e Pezão, que ainda estariam vivos. Revela que Quincas Bonfim, famoso pistoleiro de Imperatriz no Maranhão, vinha para a região para fazer trabalhos por encomenda.

A apresentação das denúncias de trabalho escravo e de existência de um cemitério clandestino no interior da fazenda modificaram a correlação de forças. Outros elementos como a produção de gêneros alimentícios pelos ocupantes e a construção de uma escola comunitária (Escola Carlos Marighella) de ensino básico no local, que outrora era utilizado como dormitório de trabalhadores 
escravizados, foram fundamentais para segurar a concessão de novas liminares de reintegração de posse $^{9}$. A permanência na terra, a mudança de governo no plano federal (Governo Lula) e a construção de uma narrativa camponesa que conseguiu se fazer legítima e ser assumida como narrativa oficial possibilitaram a desapropriação de Cabaceiras e a criação do Assentamento Rural 26 de Março.

A ação possessória durou até a imissão do INCRA na posse, em 2008, e foi um lugar privilegiado de disputa e observação sobre narrativas de classes e usos da terra. Ao longo dos anos, tentativas de despejo e resistência por parte dos camponeses foram descritos nos autos do processo judicial, revelando as estratégias utilizadas para conferir legitimidade à luta naquela ocupação coletiva. Por fim, teceram uma nova história a ser rememorada.

\section{CONSIDERAÇÕES FINAIS}

A luta por Cabaceiras oferece elementos para uma reflexão sobre a idealização da técnica, que na visão de Benjamin também estaria no cerne da possível morte da narrativa. Até a entrada do MST, a fazenda, embora já houvesse sido considerada improdutiva segundo os índices utilizados pelo INCRA, era conhecida pela criação de gado Nelore e por ser uma das primeiras empresas a trabalhar com fertilização in vitro na região. Pela aparência, os índices de produtividade do imóvel seriam sempre excelentes e o progresso parecia instalado, encobrindo as contradições inerentes ao processo de aprimoramento e modernização da pecuária, como ocorre em toda aquela região.

A denúncia feita pelos trabalhadores rurais sem-terra apresentou 'uma outra história possível', uma narrativa camponesa questionadora, que foi capaz de deslegitimar as práticas predatórias das empresas da família Mutran. Enfrentando o discurso modernizador da técnica, o MST reconstrói espaço para o surgimento de uma nova narrativa. Utilizando o processo judicial para fazer esse enfrentamento, possibilita-se o surgimento de novas jurisprudências, abrindo caminho para possíveis modificações na forma de operacionalização jurisdicional e da noção de justo.

A narrativa proposta pelo conjunto composto por juristas e movimentos sociais traz como fio condutor a função social da propriedade. Sua dimensão trabalhista e a questão ambiental passam a ser reconhecidas como legitimas e capazes de problematizar o caráter absoluto da propriedade. O processo como documento histórico nos aponta os caminhos para percepção da proposta narrativa que revela o método do movimento social na construção de suas práticas frente à disputa das ações do Estado.

\footnotetext{
${ }^{9}$ De acordo com informantes que trabalham na escola, o local onde foi instalada teria sido construído em atendimento a um Termo de Ajustamento de Conduta (TAC) firmado com o Ministério Público do Trabalho (MPT), por conta das reiteradas denúncias de ocorrência de trabalho escravo em que os trabalhadores eram encontrados em abrigos de taipa com cobertura de palhas e sem acesso a fontes de água potável e banheiros.
} 
No caso apresentado, a narrativa de luta por Cabaceiras aponta para uma disputa sobre a estratégia de desapropriação que seria efetivada pelo Estado, mas, também, para uma tentativa de contar a própria história da luta e do movimento. Trata-se de disputa por hegemonia e da possibilidade de construção de uma narrativa pautada pelo materialismo histórico em que o ser social camponês se torna narrador e narrativa.

Com este artigo, uma possível contribuição para os estudos em movimentos sociais se resolve no oferecimento de um conjunto metodológico centrado na ideia de construção de narrativas, a partir da tradição da teoria crítica que pode ser utilizado pelos estudos jurídicos, históricos e sociológicos na América Latina. Acreditamos iniciar a construção de uma maneira própria de observar a ação coletiva a partir de uma sociologia viva, dentro de um debate que passa a ter que encarar novas configurações sobre a agência dos subalternizados. Estes, cada vez mais, se tornam portadores/produtores de narrativas, hoje, fartamente disputadas e compartilhadas no ambiente virtual da rede mundial de computadores. Resgatamos histórias e experiências de sujeitos vivos em luta, que podem nos oferecer lições importantes, na contramão do atual cenário de desmonte das políticas públicas para o campo, o meio ambiente e os direitos humanos.

\section{REFERÊNCIAS}

BENJAMIN, Walter. Magia e técnica, arte e política: ensaios sobre literatura e história da cultura. São Paulo: Brasiliense, 2012.

BOURDIEU, Pierre. O poder simbólico. Rio de Janeiro: Bertrand Brasil, 2010.

CASALDÁLIGA, Pedro. Uma Igreja da Amazônia em conflito com o latifúndio e a marginalização social. São Félix do Araguaia, 1971. Disponível em: http://www.servicioskoinonia.org/Casaldaliga/cartas/1971CartaPastoral.pdf. Acessado em $16 / 05 / 2016$.

FREITAS, Emmanuel Oguri. A Devolutiva como Prática Dialógica/Dialética da Sociologia Viva do Observatório Fundiário Fluminense: O caso da luta pela terra na Fazenda Cabaceiras. Confluências, Niterói, v. 21, n. 2, p. 179-195, ago. 2019.

GINZBURG, C. El juez y el historiador: Consideriaciones al margen del processo Sofri. Traducido por Alberto Clavería. Madrid: Anaya \& Mario Muchnik, 1993.

GUERRA, Gutemberg Armando Diniz. O posseiro da fronteira. Belém: Editora Paka-Tatu, 2013.

IANNI, Octavio. Colonização e Contra-Reforma Agrária na Amazônia. Petrópolis: Vozes, 1979.

KAYE, Harvey J. The British Marxist Historians. New York: Palgrave Macmillan, 1984

MOTTA, Márcia Maria Menendes. Nas Fronteiras do Poder: conflitos de terras e direito agrário no Brasil de meados do século XIX. Rio de Janeiro: Vício Leitura/Arquivo Público do Estado do Rio de Janeiro, 1998.

MOURA, Margarida Maria. Os herdeiros da terra: parentesco e herança numa área rural. São Paulo: Hucitec, 1978. 
PARÁ. Tribunal de Justiça. Ação Possessória nº28.1998.1.001033-1, Vara Agrária de Marabá, 1998.

QUINTANS, Mariana Trotta Dallalana. Poder judiciário e conflitos de terra: a experiência da vara agrária do sudeste paraense. Rio de Janeiro, 2011, 278 f. Tese (Doutorado em Ciências Sociais em Desenvolvimento, Agricultura e Sociedade) UFRRJ, 2011.

ROSA, Marcelo. REFORMA AGRÁRIA E LAND REFORM: movimentos sociais e o sentido de ser um sem-terra no Brasil e na África do Sul. CADERNO CRH, Salvador, v. 25, n. 64, p. 99-114, jan./abr. de 2012.

SAKAMOTO, Leonardo. Os negócios da família Mutran. Disponível em: http://www.cartamaior.com.br/?/Editoria/Direitos-Humanos/Os-negocios-da-familiaMutran/5/1169. Acesso em: 12 mai. 2016.

SIGAUD, Lygia. Direito e coerção moral no mundo dos engenhos. Estudos Históricos, Rio de Janeiro, v. 9, n. 18, p. 361-388, dez. 1996.

. A forma acampamento: notas a partir da versão pernambucana. Novos Estudos Cebrap, São Paulo, v. 3, n.58, p.73-92, nov. 2000.

THOMPSON, E.P. A miséria da Teoria ou um planetário de erros: uma crítica ao pensamento de Althusser. Rio de Janeiro: Zahar Editores, 1978.

. Costume, Lei e Direito Comum. In: Costumes em Comum: Estudos sobre a cultura popular tradicional. São Paulo: Companhia das Letras, 1998.p. 86-149.

VARELLA, M. D.. O MST e o Direito. In: MOLINA, Mônica Castagna et al. Introdução crítica ao Direito Agrário. Brasília: UNB, 2002. 